\title{
A CHEMICAL AND \\ HISTOCHEMICAL STUDY OF DPN-DIAPHORASE ACTIVITY IN THE ADRENAL CORTEX OF THE DEVELOPING MOUSE ${ }^{1}$
}

\author{
JOHN M. ALLEN \\ Department of Zoology, University of Michigan, \\ Ann Arbor, Michigan \\ EIGHT FIGURES
}

Histochemical study of aliesterase activity in the adrenal cortex of the developing mouse has provided new information concerning the activity of the X-zone (Allen, '58). This work indicated that aliesterase in the $X$-zone reached maximum activity between 7 and 14 days after birth. By 21 days of age the activity of the enzyme in this tissue had dropped to low levels and remained so throughout the remainder of the period studied. These observations indicated that further study of the $\mathrm{X}$-zone using enzyme localizing techniques might prove interesting. The present paper reports the time-course of development of diphosphopyridine nucleotide (DPN) diaphorase activity in the $\mathrm{X}$-zone and permanent cortex of developing mice.

\section{METHODS}

All work was carried out on adrenal glands from BALB/c Jax mice. Newborn and older animals were dated in reference to time of birth as determined by animal inspection at 0800 hours and 2000 hours. DPN-diaphorase was determined histochemically by a slight modification of the Farber et al.

\footnotetext{
This research has been supported by a grant from the U. S. Public Health Service (C-2751 C-2). The microtome cryostat, the Beckman Model DU spectrophotometer and attachments were purchased with funds provided by a grant from the H. H. Rackham School of Graduate Studies of The University of Michigan.
} 
('56) method. The substrate solution contained the following: $64 \%$ ethanol, $2.0 \mathrm{~cm}^{3} ; 0.1 \mathrm{M}$ phosphate buffer $\mathrm{pH} 7.4,8.0 \mathrm{~cm}^{3}$; $10 \mathrm{mg}$ DPN (Sigma); $7 \mathrm{mg}$ Blue Tetrazolium (General Biochemicals); $1.5 \mathrm{mg}$ partially purified alcohol dehydrogenase (Sigma); water, $20 \mathrm{~cm}^{3}$. The substrate solution was gassed with nitrogen before and during incubation of tissue sections. Tissues for histochemical study were sectioned at $10 \mu$ in a microtome cryostat at $-20^{\circ} \mathrm{C}$. Prior to sectioning these tissues were quick frozen by placing them in a test tube immersed in a slush of dry ice and acetone. Sections were mounted on glass slides with no adhesive. Chemical fixatives were not employed. Before immersion in the histochemical substrate solution these sections were removed from the cryostat, rapidly dried in an air jet, and defatted in acetone at room temperature for 30 seconds. The acetone extraction greatly improved the sharpness of the reaction and did not appear to affect the intensity of the histochemical reaction. Optimum incubation time for these sections was 10 minutes at $37^{\circ} \mathrm{C}$. Substrate solutions containing no DPN served as controls. Sections incubated in such solutions showed no histochemical reaction. Histochemical analysis was carried out on 10 animals equally divided between the sexes for each age period studied. Results were immediately recorded on Ektachrome film since the preparations rapidly deteriorated.

DPN-diaphorase was determined chemically by the method of Mahler (' 55 ). The substrate solution contained the following final concentrations of reactants : $0.03 \mathrm{M}$ phosphate buffer $\mathrm{pH} 7.4 ; 0.001 \mathrm{M}$ reduced DPN (Sigma); $0.003 \mathrm{M}$ potassium cyanide; $0.00033 \mathrm{M}$ di-chlorophenolindophenol (DIP) (National Aniline). Reduction of DIP was measured at 15-second intervals at room temperature in a Beckman Model DU spectrophotometer at $600 \mathrm{~m} \mu, 0.01 \mathrm{~mm}$ slit width, using Pyrocell $1 \mathrm{~cm}$ light path cuvettes with a capacity of $1 \mathrm{~cm}^{3}$. No substrate (DPNH) and no enzyme controls were provided. Enzyme activity was determined using crude tissue homogenates suspended in $0.9 \%$ sodium chloride. The activity of these homogenates was determined immediately after preparation. 
Total nitrogen in the samples used for quantitative analysis was determined by direct Nesslerization (Levy, '36). Color developed was measured at $460 \mathrm{~m} \mu$ using a Coleman Model $6 \mathrm{~A}$ spectrophotometer. Enzyme activity was expressed as moles of DIP reduced per milligram of total nitrogen per minute. For these calculations a molar extinction coefficient for DIP of $17.8 \times 10^{3} \mathrm{~cm}^{2} /$ mole was used (Steyn-Parvé and Beinert, '58). Data were analyzed using standard statistical methods.

\section{HISTOCHEMICAL RESULTS}

Day of birth (fig. 2). New born animals showed very low levels of DPN-diaphorase activity in all cortical cells. The enzyme activity was confined to the cytoplasm of epithelial cells and connective tissue cells were negative. No differences in activity between zones of the cortex were noted. Males and females exhibited equivalent patterns of activity.

Seven days of age ( $f g .3$ ). Slight increases in enzyme activity were noted at this time. Adrenals of some animals showed slight but obvious increases in the activity of DPNdiaphorase in the interlocking zone. Both the zona glomerulosa and the zona fasciculata were more active than on the day of birth but no differential activity between these zones could be detected. No sex difference in enzyme activity was noted.

Fourteen days of age ( $f \mathrm{~g}$. 4). The zona glomerulosa and the zona fasciculata showed a further moderate increase in activity over that noted at 0 and 7 days of age. The cells of the zona glomerulosa showed slightly higher DPN- diaphorase activity than the cells of the zona fasciculata. The most striking feature seen in the adrenal at this age was the development of intense DPN-diaphorase activity in the cells of the Xzone (interlocking zone of earlier stages). Males and females showed equivalent patterns and intensity of activity.

Twenty-one days of age (fig. 5). In females the activity of $\mathrm{DPN}$-diaphorase in the $\mathrm{X}$-zone dropped to very low levels. In males still showing a remnant of the $\mathrm{X}$-zone, activity of the enzyme was equivalent to that noted in females. In the 
cells of the permanent cortex DPN-diaphorase activity was comparable to that seen in males at 90 days of age. The zona glomerulosa showed a marked increase in activity over that noted at 14 days of age. The cells of the outer zona fasciculata retained activity levels comparable to those seen at 14 days of age. The inner zona fasciculata, however, became distinguished by the acquisition of high levels of enzyme activity. The activity of DPN-diaphorase in this inner zone of the fasciculata was only slightly less than that seen in the zona glomerulosa. Other than the nearly complete loss of the $X$-zone in males the patterns and intensity of activity in males and females were comparable.

Twenty-eight days of age (fig. 6). No further alteration of the situation just described for animals 21 days of age was apparent.

Ninety days of age (figs. 7 and 8). No change in the intensity or in the pattern of DPN-diaphorase activity was noted in the adrenal cortex of males. In the female a marked intensification of enzyme activity was noted in the zona fasciculata. Particularly affected was the region of the outer fasciculata which showed low activity in both sexes at 21 and 28 days of age and which remained low in males 90 days of age. Activity in the zona glomerulosa was equivalent to that noted at 21 and 28 days of age. Activity in the $\mathrm{X}$-zone remained low.

\section{QUANTITATIVE RESULTS}

The results of quantitative determinations of DPN-diaphorase activity are presented graphically in figure one. These results confirmed the histochemical observations reported above. Inspection of this figure indicates a slight increase in the activity of DPN-diaphorase activity between 0 and 7 days of age. The t-test indicated this increase to be insignificant $(\mathrm{P}=0.1)$. At 14 days of age a significant increase in the activity of the enzyme over that noted at 0 and 7 days of age occurred $(\mathrm{P}<0.01)$. The activity of DPN-diaphorase noted at 14 days of age was significantly less than that at 21,28 , and 
90 days of age $(\mathrm{P}<0.02)$. Levels of activity seen at 21 and 28 days of age were equivalent $(P=0.7)$ and were not significantly different from levels of activity prevailing in 90 day-old males and females $(P>0.2)$. No sex difference existed between animals $0,7,14,21$, and 28 days of age $(\mathrm{P}>$ 0.2 ). Therefore, for the purposes of calculation, data from males and females of these ages were pooled. A significant difference in activity between 90-day-old males and females did exist $(\mathrm{P}<0.05)$.

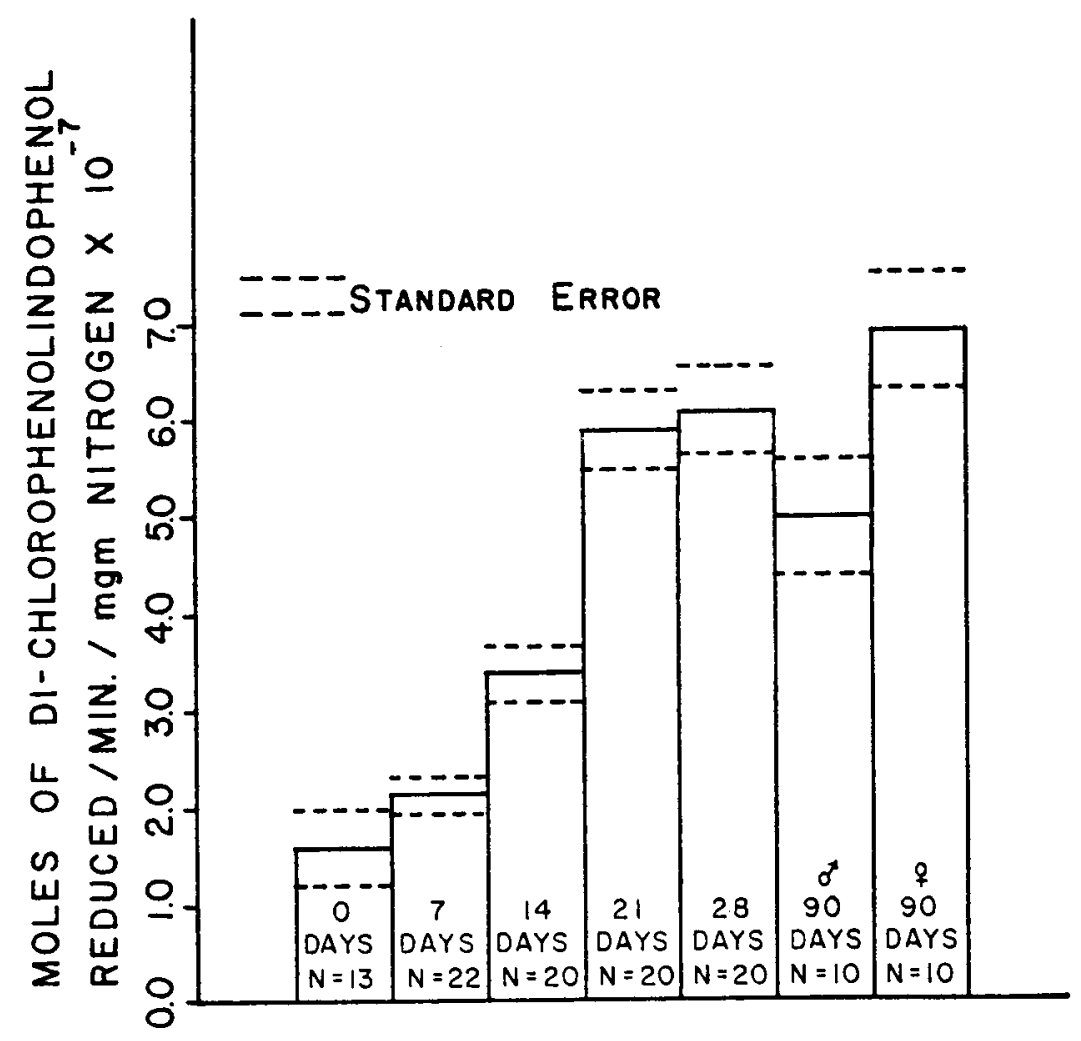

\section{AGE IN DAYS AFTER BIRTH}

Fig. 1 Graph showing relation of the DPN-diaphorase activity in whole homogenates of adrenals to age in days after birth. $\mathrm{Y}=$ number of unimals per group. Data for males and females have been pooled except for that derived from animals 90 days of age. 


\section{DISCUSSION}

The above results indicate that DPN-diaphorase activity reaches its maximum levels in the $\mathrm{X}$-zone about 14 days after birth. A similar course of events has been demonstrated for aliesterase activity in this region (Allen, '58). Even though the significance of these results is unknown three areas for speculation present themselves:

1. Association of this enzyme activity with hormone production. Association of either aliesterase or DPN-diaphorase activity with hormone production in the $\mathrm{X}$-zone is not warranted. Although levels of aliesterase activity have been shown to parallel the secretory status of the zona fasciculata and the zona glomerulosa in the adrenal cortex of the adult mouse (Allen, '57) no evidence exists indicating a direct role for the enzyme in steroid production. A possible role in general lipid metabolism seems more likely (Ammon and Jaaram, '万0). DPN-diaphorase (as cytochrome c reductase, Mahler, '55) is important in oxidative phosphorylation and levels of activity of this enzyme may reflect general metabolic status.

Howard ('39) has shown that orchidectomy 5 days after birth results in hypertrophy of the $\mathrm{X}$-zone in male mice. In these animals the epithelium of the seminal vesicles continued to increase in height. These facts suggested the presence of an extra-testicular source of androgen. It was postulated that the source of this androgen might be the $\mathrm{X}$-zone. The proposed production of androgen by the X-zone of young orchidectomized mice correlates well with the increased levels of enzyme activity noted between 7 and 14 days of age, but continued androgen production (for at least 50 days) does not correlate with the drop in enzyme activity noted at 21 days of age. Perhaps the X-zone in the castrated male behaves differently from an enzymatic point of view than in the normal animal.

Preliminary, unpublished observations in this laboratory indicate that the $\mathrm{X}$-zone of the 14-day-old mouse contains no DPN-diaphorase coupled beta-steroldehydrogenase activity 
(Wattenberg, 58). Moderate levels of activity were found in the cortical cells. Since this enzyme system is implicated in an early stage of androgen synthesis (Wattenberg, '58) it appears unlikely that androgen production in the X-zone, if it occurs, takes place through the DPN-diaphorase betasteroldehydrogenase link.

2. Association of the enzyme activity with an unknown function of the X-zone. A striking feature of both DPN-diaphorase and aliesterase activity in the $X$-zone of the mouse is the drop which occurs between the 14th and 21st day of development. This depression of activity coincides with the time at which the cells of the permanent cortex develop full functional capacity (Allen, '57; Moog, '53, '54). This coincidence may indicate that the $\mathrm{X}$-zone is performing a function, as yet unknown, which is later taken over by the cells of the permanent cortex.

3. Association with growth processes in the X-zone. Finally, it should be noted that the high levels of enzyme activity noted in the $\mathrm{X}$-zone between the 7 th and 14th day of development may reflect metabolic activity associated with growth taking place in this zone at this time (Waring, '35).

Both chemical and histochemical determinations of DPNdiaphorase in the cells of the permanent cortex indicate that adult levels of activity are reached by the 21st day of development. These results differ from those obtained for aliesterase activity (Allen, '58). In this latter case the enzyme reached adult levels of activity in the zona fasciculata as early as 14 days of age. In the zona glomerulosa attainment of adult activity levels was delayed until about the 28 th day of age. Apparently aliesterase and DPN-diaphorase follow different ontogenetic patterns. Until DPN-diaphorase has been subjected to physiological modifications such as those employed in the analysis of aliesterase activity (Allen, '57) its relation to secretory phenomena in the adrenal cortex will remain unknown.

In conclusion, attention should be called to the apparent sex-difference noted in DPN-diaphorase activity. This en- 
zyme thus joins alkaline phosphatase (Allen and Slater, '56) and aliesterase (Allen, '58) in this respect. The significance of these differences in enzyme activity between the sexes is unknown.

\section{SUMMARY}

DPN-diaphorase activity in the adrenal cortex of the mouse has been investigated at $0,7,14,21,28$, and 90 days of age using chemical and histochemical methods.

Histochemical studies showed a homogeneous distribution of low levels of enzyme activity at 0 and 7 days of age. Some animals at 7 days of age showed a slight elevation of enzyme activity in the interlocking zone. By 14 days of age high levels of activity emerged in the X-zone. The cells of the cortex at this time showed levels of activity only slightly higher than those noted at 0 and 7 days of age. By 21 days of age enzyme activity in the $\mathrm{X}$-zone had dropped to low levels. Adult levels and patterns of activity had, however, emerged in the permanent cortex by this time. In the permanent cortex the enzyme showed highest activity in the zona glomerulosa and in the inner region of the zona fasciculata. Animals 90 days of age showed a marked sex-difference in enzyme activity. This involved the outer zona fasciculata of the female and this region showed higher levels of activity than in the male. Quantitative determinations of DPN-diaphorase activity confirmed the histochemical observations. The relation of these results to the physiology of the $\mathrm{X}$-zone and the permanent cortex is discussed.

\section{LITERATURE CITED}

ALLEN, J. 1957 A chemical and histochemical study of aliesterase in mouse adrenal cortex under hormonal influences and altered sodium intake. Endocrinol., 61: 368-374.

1958 A chemical and histochemical study of aliesterase in the adrenal gland of the developing mouse. Anat. Rec., 132: 195-208.

ALLEN, J., AND J. SLATER 1956 Influence of hormones upon the distribution of alkaline phosphatase in mouse adrenal cortex. J. Histochem. Cytochem., 4: 110-117. 
AMMON, R., AND M. JAARMA 1950 Enzymes hydrolyzing fats and esters. In: The Enzymes I. Ed. J. Sumner and K. Myrbäck. Academic Press, Ine., New York. Chap. IX, pp. 390-442.

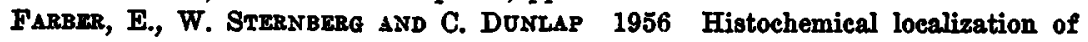
specific oxidative enzymes. I. Tetrazolium stains for diphosphopyridine nucleotide diaphorase and triphosphopyridine nucleotide diaphorase. J. Histochem. Cytochem., 4: 254-265.

HOWARD, E. 1939 Effects of castration on the seminal vesicles as influenced by age, considered in relation to the degree of development of the adrenal X-zone. Am. J. Anat., 65 : 105-149.

LEVY, M. 1936 Studies on enzymatic histochemistry. XVII. A micro-Kjeldahl estimation. C. R. trav. Carlsberg, Ser. chim., 21: 101-110.

Mahler, H. 1955 Diaphorases. In: Methods in Enzymology, Vol. II. Ed. S. Colowick and N. Kaplan. Academic Press, Inc., New York, p. 707.

MOOG, F. 1953 The functional differentiation of the small intestine. III. The influence of the pituitary-adrenal system on the differentiation of phosphatase in the duodenum of the suckling mouse. J. Exp. Zool., 124: $329-346$.

Moog, F., D. BennetT and C. DEAN 1954 Growth and eytochemistry of the adrenal gland of the mouse from birth to maturity. Anat. Rec., 120: 873-892.

STEYN-PARTE, E., AND H. BEINERT 1958 On the mechanism of dehydrogenation of fatty acyl derivative of coenzyme A. J. Biol. Chem. 23s : 843-852.

Waring, H. 1935 The development of the adrenal gland of the mouse. Quart. J. Micr. Sei., 78: 329-366.

Watrenbero, L. 1958 Microscopic histochemical demonstration of steroid-3. beta-ol dehydrogenase in tissue sections. J. Histochem. Cytochem., 6. 225-232. 


\section{PLATE 1}

EXPLANATION OF FIGURES

All photographs represent a magnification of $100 \times$. Prints and the negatives used to produce them were copied from original Ektachrome transparencies. All exposure and processing times were held to constant values.

2 DPN-diaphorase activity in the adrenal of a newborn male mouse. Very low levels of activity are present in all cortical cells.

3 DPN-diaphorase activity in the adrenal of a 7-day-old male mouse. Slight increase in enzyme activity may be noted in the interlocking zone. Activity in the permanent cortex is slightly higher than that seen at 0 days of age.

4 DPN-diaphorase activity in the adrenal of a 14-day old female mouse. The $X$-zone shows high levels of activity but the cells of the permanent cortex are only a little more active than those seen at 7 days of age. No marked difference in activity is apparent between the zone glomerulosa and the zona fasciculata.

5 DPN-diaphorase activity in the adrenal of a 21-day-old female mouse. Activity in the $X$-zone has again dropped to low levels. Activity in the permanent cortex is comparable with that to be seen in the 90-day-old male (fig. 7 ). Note the high activity present in the zona glomerulosa and in the inner region of the zona fasciculata. An identical pattern of activity is seen in the 21-day-old male.

6 DPN-diaphorase activity in the adrenal of a 28-day-old female mouse. Activity pattern is equivalent to that seen at 21 days of age (fig. 5).

7 DPN-diaphorase activity in the adrenal of a 90-day-old male mouse. No marked change in the intensity and distribution of the activity is apparent over that noted at 21 and 28 days of age.

8 DPN-diaphorase activity in the adrenal of a 90-day old female mouse. Note the marked increase in intensity of enzyme activity in the outer areas of the zona fasciculata as compared to the male of the same age (fig. 7). Activity in the $X$-zone is equal to that noted at 21 and 28 days of age. 
DIAPHORASE IN DEVELOPING ADRENAL JOHN M. ALLEN
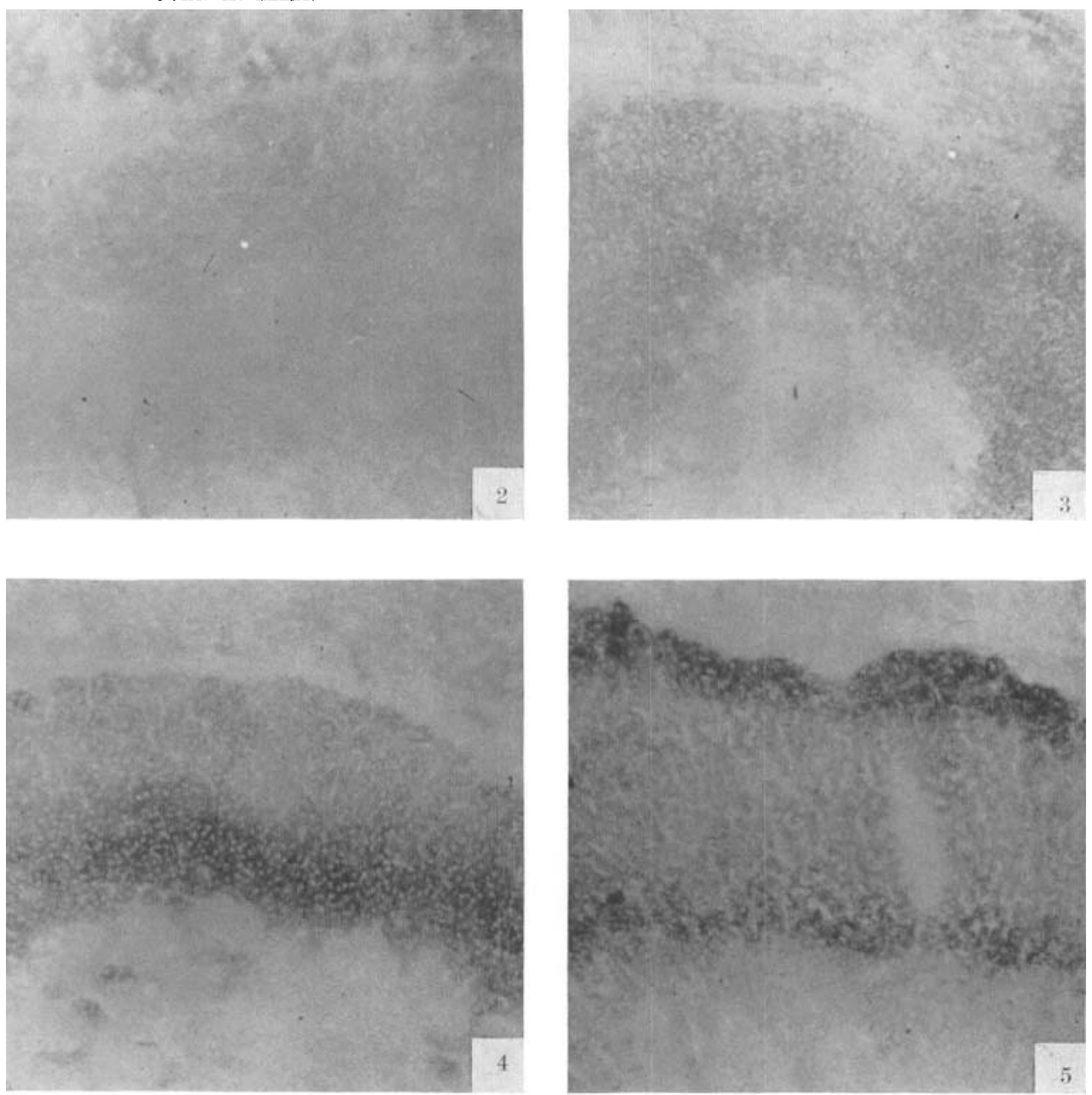
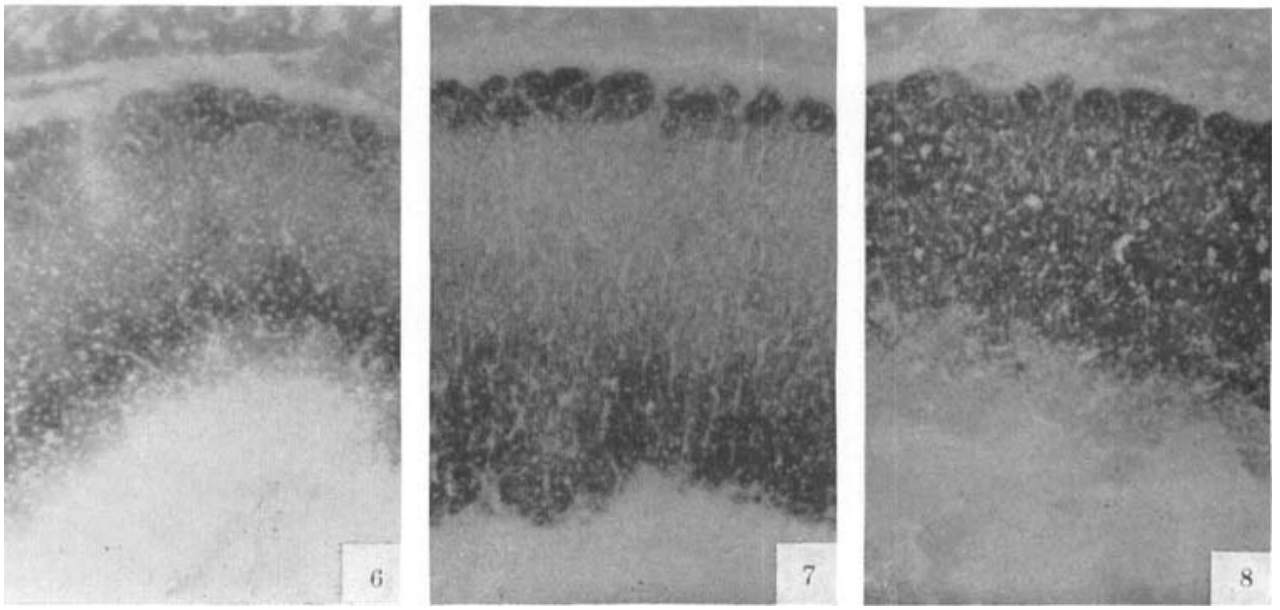